\title{
A Third Space Research Methodology Through the Metaphor of Mokshya
}

\author{
Suresh Gautam* and Bal Chandra Luitel \\ School of Education, Kathmandu University, Lalitpur, Nepal
}

\begin{abstract}
In this paper, we argue that research paradigms arising from the Western Modern Worldview (WMW) orient research enterprise to serve metaphysics of presence (positive evidence), propositional, deductive and analytical genre and logics (Luitel, 2003), thereby privileging knowing as misappropriating local knowledge system. When the WMW fails to understand the connectedness within local worldviews, they are like colonization. Many researches are taken for granted to put all in boxes creating a dualism of the West (colonized) and non-West (decolonized ${ }^{2}$ ). However, the dualism of the West and the Rest hardly recognizes the multiple realities of the local people. In so doing, we envision Third Space Research Methodology where we can realize the importance of both the West and the Rest drawing from their best practices. Developing such a methodology allows all voices to be heard but take precedence over the indigenous/local voice rather than the voice of the researchers. This is why, we suggest a Third Space (Mokshya- an interest of emancipation) methodology through breaking the hierarchies of the West and the local. We use a metaphor of Mokshya describing the Eastern (Hindu/Baudhhist/Jain/Sikhs) epistemic view to be aware of the colonial and decolonial parameters of research.
\end{abstract}

Keywords: Decolonial, third space, research paradigm, Mokshya-metaphor of liberation

\section{All the Roads Lead to Smith}

For the first time, I (Suresh Gautam) came across the term 'decolonizing research methodology' when I was studying literacy practices of Tharu people in 2011. During my initial reading of Smith (1999), I realized that decolonizing research methodology is employed for dismantling hierarchies between the Western and the non-Western epistemologies that exist in the research processes. Decolonial research methodology is 
believed to 'liberate' researchers from the universalized approach of research dominant with 'Western Enlightenment'. Smith's work makes me contemplate on the dominant research paradigms that followed the Western Modern Worldview (WMW). I assessed different research paradigms and how research paradigms became de $/ 3$ colonial to produce the universal, objective and neutral epistemic world views through meta-narratives. In order to be liberated from the WMW, decolonial research methods appeared as the liberation. However, my concern is to raise a query about how these research paradigms enable researchers to capture the voice of the voiceless people in the research area. Moreover, how far it is possible for the rest of the paradigms to delink from the WMW is yet another concern.

All the roads of research are led by positivism in the social and educational research. During the time, post-positivism emerges suspecting the knowledge generated by positivism. The shift from positivism to post-positivism may be the first stage of decolonization of research. Similarly, the paradigm shift from post-positivism to interpretativism to post modernism may have some features to suspect. Relating to the origin and spread of decolonial thinking, Madonado-Torres (2011) states:

Decolonial thinking has existed since the very inception of the modern form of colonization, and, to that extent, a certain decolonial methodology has existed as well and possibly more profound shift from modernization towards decoloniality as an unfinished project took place in the twentieth century and is still unfolding now. (pp. 1-2)

Because all research paradigms suspect the previous one to be the best one. Along this line, decolonial thinking exists since it started from the beginning of the early nineteenth century as it has been suspected since its inception in the West. Thus, I argue that the de/colonial research methodologies are the products of the 18th and 19th century colonizing process. Accordingly, modernism may carry the legacy of colonialism. However, "the decolonial turn does not refer to a single theoretical school, but rather points to a family of diverse positions that share a view of coloniality as a fundamental problem in the modern, postmodern and information age" (Madonado-Torres, 2011, p. 2). Hence, I understand the term decolonial as an umbrella term that includes specific indigenous and local perspectives in the research methodology. In this context, I ask a question: how far are these Indigenous/Local practices prevailing in decolonial research design? It would be another research work to explore how much indigenous value the traditional people follow? Has the 
vicious circle of imperialism been spreading over the Indigenous community? In addressing these as well as many other questions, I worked with my mentor, Bal Chandra Luitel, whose role could be described by the designer of the metaphor, a role which is complemented by a builder. We attempt to envision the emancipation via the metaphor of Mokshya, thereby, assessing the key research paradigms.

\section{Thinking 'Mokshya' in Research: A Way to Justice}

We have taken Mokshaya as a metaphor of being aware of colonial practices in the WMW research traditions that may not be able to explore the social complexities. In this sense, the metaphor of Mokhsya is helpful to see beyond the WMW as it is taken as "freedom ... and the attainment of supreme ... bliss" (Sivananda, 1994). The notion of freedom is to utilize ways of knowing embedded in the context of the researcher. We argue here that Mokshya enables researchers to become aware of the hegemony of the WMW-inspired knowing as imposing one set of categories onto the world as if those categories are full and final.

Decolonial research tradition can be considered a movement towards recognizing the local epistemologies instead of universalized ones that have been doomed in a shadow of positivism. Decolonial research tradition can be regarded as an organized form of 'epistemic disobedience' (Mignolo, 2009). Thus, proponents of research paradigms and methodologies arising from decolonial research traditions criticize the WMW in terms of its hegemonic instances (Maldonado-Torres, 2011). Along similar lines, Smith (1999) argues, "Research" probably being one of the dirtiest words in the Indigenous world's vocabulary (p. 1) while showing the dominance of the WMW. Research itself has been presented as a Western construct in a way of producing and legitimating knowledge of the world. In this case, it is not difficult for us to interpret Smith from the anti- colonial perspective because she believed that traditions of researches were mostly guided by the WMW to explore the history of exploitation and unequal power relationships in the Indigenous Maori community.

\section{Colonialism in the Research Methodology: Epistemic Injustice}

Colonialism started as a burden of the colonizer's interest such as religious, social, cultural and economic assimilation from the West. The colonizers abducted the local (cf. indigenous) peoples' freedom and compelled them to live in an oppressive situation in the colonial period. "Colonization involved the imposition of language, religions, political 
organizations and cultural practices, as well as using colonized populations as cheap labour to enhance profit in capitalist enterprises" (Gribch, 2004, p. 7).

Although the form of colonialism is different in our case ${ }^{4}$, right from the beginning, colonization was started by capturing land and imposing authority on the local people. The forms of colonization did not only expand in the geopolitical territory but it equally occupied the academia by colonizing the mind of the elites. As a result, educational research and practice subscribed to the European Enlightenment in producing, legitimating and sanctioning knowledge through the positivistic metaphor of knowing as deducing from standard laws and principles developed within the framework of the Western Modern Worldview. "European Enlightenment is generally agreed that modernity emerged during the eighteenth century in Europe - a period termed the Enlightenment, although the use of logical processes of reason to challenge or support established beliefs can be linked to earlier times" (Girbich, 2004, p. 4). This long history of colonization affects the ways of thinking among people creating the image of the superior West. The imitation of the Western ways of thinking such as promotional, hypothetic-deductive still continues. At present, modernity prevails in the form of imperialism through the researches as Smith (1999) says:

[r]esearch is one of the ways in which the underlying code of imperialism and colonialism is both regulated and realized. It is regulated through the formal rules of individual scholarly disciplines and scientific paradigms, and the institutions that support them (including the state). (p. 8)

Here, I like to link the ideas of Fricker (2007) to assess the colonial frame of the research as "testimonial injustice, in which someone is wronged in their capacity as giver of knowledge" (p. 7). Testimonial injustice for me would be the research participants' assertions that are given unduly low weight of a researcher's prejudices about a social group to which local people belong. Testimonial injustice may prevail through the language of the researchers. Sometimes, it may be manifested through the ideas of the researcher creating the supremacy over the researched 'items'. In the global academia, "the word 'research' has too much racist and colonial baggage attached to it to be used in an Indigenous context" (Absalom \& Willet, 2005, p. 114). 


\section{Universalism of Meta-narrative in the Colonial Research Tradition}

Arriving at this stage, we argue that colonial tradition of research has the European Enlightenment legacy such as universalism, objectivism and neutrality of meta-narratives of the researched people. Thinking from within universalized perspectives of metanarratives, the colonial tradition manifested in the research methodologies since researchers started researching 'Others' and categorizing them from within perspectives arising from the WMW. Indeed, the word 'Other' itself reflects that the researcher who is not relational to the local people seems to come from a particular space. The tradition of seeking validation and representation played a major role to claim 'universalism' in the research paradigm as a WMW construct and colonial form. Similarly, social science research was supposed to equate to the natural science research in terms of neutral and objective representation of truth. Perhaps, this is all about positivism and crypto-positivism, the major orienting perspective of which is WMW. We believe the problems of research methodology are hidden under such neutral and objective frameworks of research. Thus, the colonial tradition has taken universalizing epistemology for granted as sufficient and necessary ways of knowing and being for colonial experiences. This results in producing/creating meta-narratives of the local people whose being might have non/essence through their narratives, reflections and the agendas of location.

\section{Narrative, Reflexivity and Agendas of Location}

Narratives, reflexivity and agendas of location are the major concerns of non-positivists. Of course, the nature of the narration and reflection may vary among these research traditions. Although many decolonial researchers are using these terms equally showing the departure of the positivism, these are equally valued for the non-positivism. Chinn (2007) used a decolonizing research methodology to study the role of culture, place and personal experiences in the professional development as a mathematics and science teacher in Asia. His methodology focuses on the fact that "science studies connecting science and society provide opportunities for personally meaningful, experiential, inquiry and place-based learning fundamental to scientific and environmental literacy" (p. 1248). Likewise, Hamdan (2009) aims at using narrative as a method to deconstruct negative images of Muslim women saying that "I highlight these narratives presented by Muslim women-narratives which serve to help decolonize the common misrepresentations of Arab Muslim women” (p. 2). Hamdan's effort to decolonize methodology focuses on the narratives of his participants. He 
would like to understand their own point of view on how their subjectivity is formed and expressed. He says, "The first aim of the paper is to use narrative to juxtapose Orientalism's ongoing association with the dehumanization of Arab Muslims with depictions and analyses of the so-called Muslim Orient”' (p. 1).

On the other hand, Bhattacharya (2009) adapted decolonizing methodologies to the study beyond narrative and cultural performances of two transnational female Indian graduate students who had been in the United States for no longer than a year. She also seemed to be a post-colonial researcher for me because she also valued the Western and local ways of understandings. On the contrary, Lincoln and Gonzalez (2008) outlined "five ways in which Western scholar might aid in decolonizing methodology and research: (a) working bilingual data, (b) considering non-Western cultural traditions, (c) multiple perspectives in texts, (d) multivocal and multilingual texts, and (e) technical issues to ensure accessibility" (p. 785). They focused more on the non- Western cultural tradition while carrying out such researches. Their ideas differ from Smith's (1999) idea to carry out researches because they opined broader cross cultural and cross lingual research strategies.

These entire four journal articles open the avenue for me to analyze decolonial research methodology. In so doing, Chin (2007) connects culture (local) and science (Western) through decolonizing methodology. In the same way, Hamdan (2009) used narrative techniques as a decolonizing methodology to examine the past experiences and decolonize minds within the Muslim community. Similarly, Bhattarcharya (2009) methodologically explores the role of performance ethnography informed by de/colonizing epistemologies to highlight the possibilities of working within/against/through contested discourses (p.1061). This way, Bhattrarchya would work on the frame of within/ against perspective as Chin (2007) did as the decolonial research methods.

Along this line, I argue that it is not a way out to be completely decolonized from the WMW. In so doing, I found a postcolonial perspective of Chin to launch local curriculum in schools. Post-colonialism transcends the collective efforts of non-Western and Western scholars to critically analyze the colonial aftermath and challenge the hegemony of the Western science (Bhabha, 1994). The word 'postcolonial' does not mean the end of the colonizing process as Quayson (2000) explains: 
To understand this process [postcolonializing], it is necessary to disentangle the term, "postcolonial," from its implicit dimension of chronological supersession, that aspect of its prefix, which suggests that the colonial stage has been surpassed and left behind. It is important to highlight instead a notion of the term as a process of coming-into-being and of struggle against colonialism and its after-effects. In this respect, the prefix would be fused with the sense invoked by "anti”. (p. 9)

In this way, I found how decolonizing research methodology needs to be bifurcated with the WMW. As with Smith's twenty-five indigenous projects, most of them focused on narratives and performances study as a decolonizing methodology. As a result, I argue that the process of understanding suitable Indigenous/ local methodologies that aim to reclaim indigenous political, cultural, economic and social self-determination goes beyond the tension of West and non-West, colonial, postcolonial and decolonial dualism to positive identities for individuals, families, communities, and nations. The root of such decolonial research moves back to the agendas of critical research to fight for their right. However, the agendas of their right and identity are relational and cultural in the decolonial research movement.

\section{Agendas of Location in (De)colonial Research}

In such circumstances, I (Suresh Gautam) found my research space (e.g., my country, my district, and my village) is problematic in the colonized, post-colonized and even in the decolonized space. Geographically we are not colonized in the span of the history of our nation. Nonetheless, I could feel the layers of colonization in my schooling, I learnt English being emphasized more than any other subjects. I like to get European and American degrees. There are many examples that I have a sense of the Western imitations. In stating this, how much do I care my nativeness is a question. At the same time, my baggage of cultural embodiment also inspires me to resist such types of cultural hegemony in my schooling. As a result, attempting to re-draw the boundary of my space in the research areas of own community and country using suitable research methods, I found decolonizing research methodology a primary tool to dismantle the hierarchies of the West and the non-west. Smith, however, critiques dominant Western discourses of knowledge and objectivity by demonstrating how Western stories and "regimes of truth" are situated within a particular cultural, social system that needs to be "decolonized"(Wilson, 2001, p. 215). Even from a novice researcher's view point, I attempt to apply a local research methodology as influenced by Smith's decolonizing methodological approaches. However, my research space as a 
researcher and participant was not similar to Smith's Maori culture of New Zealand. Unlike Maori, we have never faced direct form of colonialism. Nonetheless, we do not intend to dismantle the WMW thinking and knowing (hypothetical, deductive, and analytical) insofar as they promote empowering research enterprises. Hence, I would like to include local cosmologies that provide theoretical insights that help me understand conventional wisdom and help me analyze the local perspectives (Awasthi, 2004, pp. 84-85). So, I may not be able to completely indigenize (if this happens, this will be another form of colonialism) my knowledge based on the postcolonial theoretical analysis of my colonized space of "Othering" of the west in the research methodology.

We question how these taken for granted methodologies contributed to form a linear reproduction of the research methodology to interpret "Other" as a de/colonial form. Right from the beginning, looking at the development of social science research was heavily guided by the positivist approach and could not break the Newtonian science of analyzing the social realities. Smith emphasizes that the decolonization of research methods is "about centering our concepts and worldviews and then coming to know and understand the theory and research from our own perspectives and for our own purposes” (Smith 1999, p. 39). "Our purposes" are those of indigenous peoples, and "our own perspectives" are the indigenous approaches that allow indigenous scholars to decolonize theories, develop indigenous methodologies and use indigenous epistemology; these approaches allow scholars to make visible what is special and needed, what is meaningful and logical in respect of indigenous peoples' own understanding of themselves and the world. This entire process allows indigenous research to break free from the frames of the Western epistemologies, which, in most cases, are very different from the indigenous ones and are, indeed, suited to the Western academic thought, but which are nevertheless foreign to indigenous ways of thinking (Harvey, 2003).

\section{Degree of De/colonialism in Research Paradigms}

Arriving at this detour, we argue that there is a need for researchers to critique their own "gaze" and to reflect on the potential for their representations to be encoded as the "truth", and for alternative readings to be marginalized (Wilson, 2001, p. 215). Such ideas came to dismantle the traditional function of research as a tool of the further colonization of self and Other. How should the research be able to minimize the duality of self and other when we have prejudices of the research methodologies guided by WMW? How can we develop the 
research methodology that requires an examination of self? Whether the self has been colonized? We can envision the research methodology that explores who we are and what we need through research.

While understanding the colonizing research methodology, I (Suresh Gautam) could limit myself as a non-Westerner who is surrounded by the vicious circle of the cultural hegemony of the West. I, therefore, am habituated to set my epistemology based on the grand narratives of the West so as to carry out researches in the non-Western society while claiming democratic, just, and non-imperial/colonial societies. At the same time, my embedded cultural insights and participants' ways of knowing appear viable to blend in the various activities from the research field of carrying out the research. Such kinds of 'my' research schooling always create a tension to carry out research as I cross the comfort zone.

Here, for me, deconstructing the various power structures that secure colonial narratives and practices in a specific privilege and often of the Western space, is one of the key aspects of decolonizing methodologies and introducing a postcolonial theoretical turn to the construction and reconstruction of meaning through the past material cultures (Wobst, 2005). At the same time, I believe that post-colonial approaches of arguing cultural practices of my participants seem to be complex to include the local and traditional ways of knowing. Along similar line, Smith (1999) believes that the meta-narratives of the past histories created through postcolonial theory are often complex, difficult and steeped in a particular lexical register, the effort to decolonize a practice has, in my experience, been far more ambiguous and paradoxical.

Understanding decolonial research methodology as the need of the current academic research, I posed a few questions on the current research methodology in this section so as to identify the need of indigenous research. In so doing, I analyzed two major research paradigms: positivism and humanism (i.e., interpretive, critical and postmodern) and their colonial features that are dominant in the mainstream of the research.

\section{Positivism: Rigid Colonialism}

Positivism as rigid colonialism strictly follows the universal, objective and neutral ways of researching people. In such circumstances, I could not create my stable identity as positivist models assume that the objects of their inquiry are stable and have constitutive identity. This offers me to think on the possibility of being the objects of inquiry that are 
produced or constituted through scientific investigation. If I created my research space as an object, I would not be able to grasp the complexities of the geo-historical situatedness. In such a situation, how can I ensure my position of being non-Western in hypothesis of measurable entities that are drawn objectively and minimal space is left for new ideas that may arise during the course of the research? Thus, I believe that the positivist tradition of research is quite vulnerable in the fields of social science research, especially the researches related to indigenous norms and values. In line with Smith and others, I argue that the positivist traditions have been dominated by Eurocentrism and colonialism, prioritizing the interests of colonizer's hegemony (Luitel, 2009). Ontological assumption in positivism emphasizes and generalizes the truths defined by the community in power. These traditions are dominated by the interests of the community in power even in the research methodology. In this line, I argue that positivist approaches seem to have colonizing characteristics in power. Participants' experiences and views are given no emphasis as their views are evaluated in a uni-dimensional view of reality wrapped within the correspondence theory of reality. Thus, the loss of uniqueness and identity is viable in such research practices. We argue that positivism does not allow us to be critically aware of our positionality.

Believing that the study of the phenomenon of decolonization that concerns human beings is very different and far more complex than scientific experimentations where my space may not be very visible in this research paradigm. Thus, it is impossible to decolonize self from applying the positivist research paradigm. Challenging the reductionist myth of conceiving research design in terms of technical-procedural steps, I want to look at the complexities of indigenous nature in the research. I could better understand my research space as non/indigenous characteristics bringing my lived experiences as the primary source of evidence, thereby going beyond the readymade space of the positivist research paradigm as the sole basis of knowledge production.

Saying so, I could not claim that positivism, the replica of the Western research paradigm can be replaced by indigenous issues. Rather I argue that indigenous approaches are useful to challenge the established norms of research methodology like positivism to contribute to the body of knowledge with our own needs rather than the objects of investigation. 


\section{Humanism: Challenging Colonialism}

Following other research paradigms in humanistic research philosophy (interpretive, critical and post modernism), we experience multiple ways of thinking, being and doing Humanistic philosophy emerged as non-positivist ways of thinking and being in research. Simply, I understand humanism is 'that which is not positivism' but has other fundamental characteristics. "While positivism is wholly empirical, attributing to the researcher skills and insights not available to the research subjects, a non-positivist perspective maintains that evidence based reasoning can be used incorporating a voice for those providing the research methodology" (Alessandrini, 2012, p. 4). I may not be able to depict my complexities of being non/white and non/indigenous as a researcher and researched as following the humanistic philosophy. I apply the dualism of etic and emic perspectives, creating a distance with participants if I am adapting humanistic approach to researching. However, the development of the humanistic researches departs from the golden parameters of research methodologies (objectivism, scientific and experimental) that address my plural beings of self. I would like to bring some of the assumptions of interpretive, critical and post-modern paradigms and link how they have been de/colonized with the European ways of thinking.

All these research paradigms are set up to address the complexities of the western society rather than the non-western traditional societies. In so doing, we can envision the local ways of thinking and being which might locate the researchers and researched into the research design. It is possible through sharing the common research space. However, I feel that eastern societies demand more than one paradigm to address social, cultural and religious complexities. Along similar lines, I find that the interpretive research paradigm appears as a de/colonial form to challenge the experiment to test theories. The positivist researchers intend to maintain the experiment on human behaviour, particularly social situations are virtually impossible to replicate reliably in interpretive paradigms (Alessandrini, 2012, p. 4). If so, can we label interpretive paradigm as a decolonial tradition of doing research? However, the question exists in the ways of understanding 'Other'. How I understand 'Other' is pertinent in interpretive paradigm of research. How does the Western paradigm understand and reflect my cultural situatedness? The interpretive paradigm to me partly represents the tension of Self and Other because self has multiple layers of being and becoming so do Other. For example, my identity is always in a state of flux. When I reflect my schooling, I find myself as a White; when I think as a Nepalese, I create my image as non-white and if I situate myself as 
relational I will be indigenous. So, how is it possible just to explore the multiple realities within two categories of Self and Other employing interpretivism? Early interpretive researchers have imposed their worldview while studying the Other. In such a case, Mokshya will help us to create a space of self/other in the research space.

Similarly, if I adopt a phenomenological research methodology as Creswell (2008) describes, the researcher (I) will attempt to identify the "essence" of human experiences concerning a phenomena, as described by participants in the study (p. 15). The essence for me would again be bracketing the knowing ideology of the researchers; again it might be used for colonizing the traditional knowledge of the indigenous people. This process of phenomenology mainly stands for enlightenment ways of thinking that may fail to articulate the multiple worldviews of the indigenous world. So, phenomenology mainly supports the reductionist ways of knowing through epoche and bracketing truths instead of exploring multiple views of everyday life. Again, what I do believe here in the phenomenological inquiry may focus on the essence of extending the dualism of Self and Other. In such circumstances as a neo-colonizer, I found self is closer to the WMW rather than the Plural Worldviews. It is obvious that by collecting phenomenological data which offer a deeper understanding of both the Self and the Other's experiences thus creating meanings among them may be sufficient to understand the Decolonized epistemology via the metaphor of Mokshya.

In this context, we argue that interpretive research methodologies (phenomenology, ethnography, and hermeneutics) are part of the decolonizing methodology because they intend to focus on the subjective and inter-subjective understanding of human beings. They depart from the WMW. However, it could not be freed from the 'White Man's' burden, still the research parameters of such kinds of research are being set under the WMW. Thus, they created the dualism of interpretations that may be promoted to create a tension between researchers and participants, instead of liberating themselves.

Staying within interpretivism may not be sufficient to 'offer' justice to the underprivileged group of indigenous people so the critical paradigm exists to envision the power balance. I, therefore, believe that power structures in the society play a vital role creating a space for the researcher to explore social injustices. I know that some of the Germen philosophers developed a linear school of Marxism to think for the "poor and 
disadvantaged' from their pioneering claim to rupture the hierarchies between 'haves' and 'have nots'. On the other hand, I would like to situate myself as a critical researcher as Carspecken (1996) believes "critical epistemology hardly gives us recipes for helping the poor and downtrodden (as proposed by Westerns); it rather gives us principles for conducting valid inquiries into any area of human experience" (p. 8). It can be another cult of knowledge to understand the freedom and justice of indigenous/local people. In this line, I agree with the critical epistemology that helps to seek "alternative to what one will find in traditional social science" (Carspecken, 1996, p. 9) and feed up "evolving criticality" (Kincheloe \& McLaren, 2005, p. 304) that has occurred in the research.

Thus, I wish I could create my epistemological position that will be value mediated. In the same line, Smith (1999) offers directions to readers that may be regarded as critical communication strategies while explicitly engaging participants in examining lives, society, and institutions through the lenses of marginalized (traditional, local, indigenous, sustainable) and dominant cultures (capitalistic, consumer oriented). Critical theory research tends to emphasize relationships that involve inequities and power, and a desirable aspect of critical research involves helping those without power to acquire it (Willis, 2007, p. 82). Thus, it differs from the interpretivism as decolonial ways of thinking.

Carspecken (1996), Kincheloe and McLaren (2005) seem to be the followers of modern critical theorist. Their belief might be constructed to seek justice against the injustices created by capitalism. Such belief systems could be challenged by applying the local knowledge system. Criticalism, however, sounds inclusive in its philosophy but that philosophy for me is highly guided by the Western theories and methodologies. While arguing the space of Mokshya, criticalism may help us to advocate justice for the unjust within our context. How can I interpret the indigenous Tharu people from the Frankfurt school of thought? How will Adorno and Horkheimer help me to interpret my cultural construction of being a Brahmin elite/Subaltern? Is the philosophy of criticalism derived from the West to explore the inequalities of the East? Another growing research paradigm known as postmodern may bring the multiple voices of scholars. How about exploring the multiple voices of the participants? In this paradigm, "knowledge is understood as being fluid, impossible to cast into rigid categories", as reality is multiple and always changing. Hence, "postmodern theorists align themselves to varying and multiple theoretical frameworks by which to analyze situations" (Moosa-Mitha, 2005, p. 60). However, it has been criticized as a 
Westcentric philosophy. It may not be useful to delink the western epistemology in studying indigenous knowledge (Mingallo, 2005). It may create another layer of thinking to represent the local ways of being and doing via arts and performance.

Will Spivak ${ }^{5}$ (1988) give the answer that the subaltern can speak under the post-modern research paradigm? I think it is not possible to explore the multiple voices of the participants like subalterns under the post- modern research paradigm because the postmodern methodologies are associated with the dominant race and culture, and this cannot ensure the exploration of the voice of the voiceless people like Subalterns. Hopefully, post/modernism extends the opportunities to deconstruct the boundaries of the hierarchy; center and margin that may offer to create the plural epistemologies.

So broadly, the use of these humanistic research and analysis offers a space to explore such fragmented worldviews of Self and Other; center and periphery; powerful and marginalized, White and non-White; Western and non-Western focusing on the subjectivity of the researchers and participants. Mokshya will emancipate us to dismantle the dualism of such construct and it is possible when the researchers can value both sides of the coins during their research process. Unlike positivist, these meant to bring the subjective and humanistic worldviews that I cannot simply make generalizations from the research study. In such cases, I do not have a representative sample of the indigenous people of my society of all areas and I recognize that any interpretation of my data is shaped by my own understanding and experiences. In other words, I do not accept a positivist notion of objectivity and social phenomena because I am more impressed by Beattie (2009) who says, "My hope is that the different voices you hear throughout the book, will encourage you to fall in love with your own questions, and to engage in your own quest for meaning with imagination, courage and creativity" (p. 9). Qualitative researchers claim that it is qualitative in terms of methodology but hardly escaped from positivism as "the rules of scientific research state that it must be conducted systematically, skeptically, and ethically" (Robson, 2002). While arguing so, I recall an incident during my research. I went to the field to carry out a qualitative research to understand the perception and understanding of the rural Tharu women but I came up with a quantitative write up with a very linear way of thinking showing the causes and effects of literacy and the exploitation they experienced. Hence, I could not internalize the rigorous qualitative research process to uncover the social hierarchies. 


\section{Paradigmatic Pluralism: A Way to Mokshya}

The root of the decolonialised research tradition goes back to the critical and postmodern theories. Does it help decolonialised methodology to delink from the European civilization? Hence, I may think using decolonizing methodology to represent my shapeless identity in the research methods. I could not wish to replace the Western ways of thinking but at the same time I am sure that the Western research methods may not be helpful in exploring my shapeless identity in/through my research journey. I do not have a concrete foundation to articulate my position in the research area because my schooling has been influenced by the Macaulay ${ }^{6}$. Many times, I found myself an indigenous citizen of Nepal because my root, culture, language and identity never got mixed with other migrants. In many cases, I have compared my identity as to be a White man. The tension exists to explore who I am. In this line, I seek the solution to being relational and critical hereby adapting de/colonial research space in cultural pluralism. I understand pluralism is:

... far more than 'all people are created equal' and the 'melting pot' or the 'cultural mosaic.' It is also more than the concern for differentiation in interests and diversity; rather, as it is conceived today, it is the inverse of the melting pot: the coexistence of multiple cultural communities in one society. (Frajman, 2003)

Smith (1999), Chinn (2007) and other analysts are rejecting the universalization tendency of the Western science, and are interrogating the power dynamics and cultural assumptions inscribed upon so-called universal propositions. In this manner, they are valuing locality and the insights the process of "de-universalization" can provide in this line (Semali \& Kincheloe, 1999, pp.45-46).

Engaging difference is more empowering than a narrow focus on homogenous cultural traditions, as I realized that it should be cultivated as a catalyst to creativity and insight. Therefore, one of the most important aspects of an indigenously-informed research methodology may be apt by using their (our) indigenous perspectives to examine knowledge, and knowledge production as a discourse. In this line, I argue that transformative research may suit to explore the shapeless identity because it may involve me to problematize research as a significant site of the struggle between the interest and knowing of the West and interest and knowing of the Other (Smith, 1999, p. 2). I can focus on the small 'p' philosophy (Luitel, 2009) informed by the research participants and their knowledge systems. This may lead the 
relational being to promote the diversity and justice in the society. I can write narratives, proverbs, folktales, stories, mythology and relational cultural experiences in the research space.

Similarly, decolonizing methodology may offer me a space to produce new research methods for studying and recording traditional knowledge and indigenous people. At the same time, I can choose a path to develop the interaction between non/indigenous epistemologies and western epistemologies for the purpose of finding new methods to produce knowledge (Semali \& Kincheloe, 1999, pp. 4-5).

In such a space, I envisioned a metaphor of liberating dualism of colonial and decolonial research methods through the metaphor of Mokhsya. Mokshya is the state of awareness where researchers can judge them how far they succeed to create inclusion, fairness and justice in the research area. Mokshya, may appear as the transformative research paradigm otherwise, as Taylor (2008) postulates "within a single paradigm research design space, the task of the (colonized) graduate research student is to 'fill in the blanks' of a methodological template, focusing mainly on quantitative data collection and analysis methods, supplemented perhaps by a qualitative research component" (p. 5). Thus, transformative research paradigm will be useful for liberating ourselves to decolonize our local and contextual understandings. As Mokshya, on the other hand, a multi-paradigmatic research design space, provides freedom of (well informed) choice, and the potential for transformative research design creating a new and dynamic space, I called it here the third space.

\section{Liberations From the Paradigm: A Conclusion of Mokshya}

'Decolonizing' methodology is the unfinished project that challenges the previous established knowledge whatever it is. Unlike Smith (1999), it does not only resist the WMW but also accepts certain features that are applicable to researching local people and culture. It is as broad as Mokshaya to be receptive and perceptive. But at this stage, I dream the way to reach the local community with such a metaphorical methodology. Then, where does my skepticism on existing knowledge lead to? Even, I cannot be ready to believe that all growing research paradigms contribute to decolonizing methodology to get rid of the universal, objective meta-narrative as a prescribed research methodology. However, I am sure that the degree would be varying in the de/colonizing process. It may lead us to envision the complex

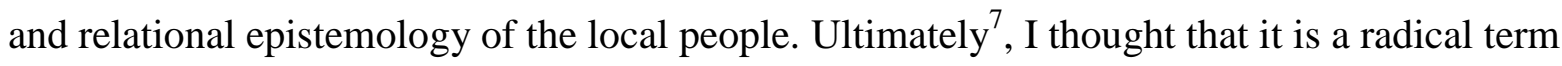
to resist against the existing scenario of research practice because every popular culture was 
the part of colonization in the post/colonial era. Believing "de/colonizing epistemologies where binaries were disrupted" (Bhattacharya, 2009), Mokshya (Third Space research methodology) may recognize possible local ways of thinking and knowing. I think that there are multiple binaries such as the binary of $\operatorname{Varnas}^{8}$, castes, genders and ethnicities in the prevailing research methodologies.

In my case, I, as a non/indigenous ${ }^{9}$ researcher, mostly prefer to continue a western ethnocentric view to 'legitimate' knowledge fitting in the Western framework, and have value for the dominant non-indigenous culture. I believe so because of my Western mode of schooling. I, therefore, understand the term "colonization" most of the time as the expansion of European culture and cultural hegemony of modernization. I feel how my cultural practices have been doomed in front of the European civilization. Many times I felt doomed in front of the white skin. That may be one of the causes of thinking the term 'decolonize' as essential strategies and research projects (Smith, 2001). However, perception to understand European civilization as white male centered may not be sufficient to interplay with the decolonizing politics.

Moreover, my sub-conscious mind often pokes me to seek my root, my origin and my traditional/spiritual/cultural heritages (Gautam, 2011). May my ideological illusion in post capitalistic humanism be lamenting on the loss of my root. In this situation, I find the Third Space methodology appropriate to dismantle the hierarchy between not only the East and the West but the complexities of Varna, caste, gender and other forms of existing hierarchies. At this stage, I will be aware of colonial and post-colonial trend of doing a research. Possibly, the Third Space methodology helps me to know myself and my cultural situatedness. With this assumption, I would like to work on it. Right from the beginning of my research career as a novice researcher, I feel it is very difficult to dismantle the positivist approach of writing in my research papers and assignments. However, I like to talk about decolonizing in methods and theory. In this journey to inquiry, I was disempowered by a priori frames (Luitel, 2009) of the theories and literatures. I am in search of the objective truth that lies out there somewhere in the physical world or the social-realist world. The truth is perfect and uncontestable as guided by the Newtonian view of action and reaction; as there is an Action there is a definitive reaction in this situation on how far I can decolonize myself from the golden standards of research paradigm and debate. 
Understanding decolonizing methodologies as an epistemically disobedient as Mignolo (2005) believed to depart from the already familiar notions of situated knowledges is visible in the linear research paradigms. However, this may not be enough to give respect to the local people. In some cases, my understanding of the research methodology as a colonized form might be useful to understand the local people's perspectives. So, I hardly set the scale to measure the perceptions and worldviews of the indigenous and local people, and we (I) believe other alternative logics- logics of graphic portrait, poetic, dialectic and dialogic and reflexivity can portray the local and indigenous flavor in the colonized world. To provide multi-dimensional or holistic understanding of the subject of inquiry, I can draw methods from the field, among the participants and even from the multiple research paradigms to offer multi-perspectives in researching.

\section{Notes}

1، Mokshya" means liberation from the cycle of death and rebirth in the Hindu philosophy. Using this metaphor of liberation, we have envisioned the state of research where we will be aware of colonial and decolonial research approach recognizing the value of the local people.

${ }^{2}$ Decolonial turn simply advocates reversing the process of colonization.

$3 /$ sign refers to the dialectical ways of thinking.

${ }^{4}$ Colonialism in Nepal was/is not geographical but it has appeared along with the development plans and policy. For example first Nepali education plan started with the Wood Commission and the first development plan started with the foreign investment and serving their purpose.

${ }^{5}$ In "Can the Subaltern Speak?" Gayatri Spivak is criticizing the intellectuals and their "desire for subjectivity". Spivak claims that "research" or "knowledge" have served as a prime justification for the conquest of other cultures and their enslavement, as part of the European colonial project.

${ }^{6}$ Macaulay wrote in his minute "we must at present do our best to form a class of persons Indian in blood and colour and English in taste, opinions in morals and in intellect."

${ }^{7}$ My positivistic reflection: Still I have 'ultimate' kind of understanding(:)

${ }^{8}$ Varna- Vyavastya is the system of division of labour originally based on aptitude an capability.

${ }^{9}$ I practice dialectical logic to argue that I am indigenous and non indigenous at the same time.

\section{References}

Absolon, K., \& Willet, C. (2005). Putting ourselves forward: Location in Aboriginal research. In L. Brown \& S. Strega (Eds.), Research as resistance: Critical, indigenous and antioppressive approaches. Toronto: Canadian Scholars' Press. 
Alessandrini, M. (2012, July). Non positivist approaches to research in the Third Sector: Empowered policy-making. Paper presented at the annual meeting of the ISTR 10th International Conference, Universita Degli Studi Di Siena, Siena, Italy.

Awasthi, L. D. (2004). Exploring monolingual school practices in multilingual Nepal

(Unpublished PhD dissertation). Danish University of Education Copenhagen, Denmark.

Beattie, M. (2009). The quest for meaning: Narrative of teaching, learning and the arts.

Rotterdam: Sense Publishers.

Bhabha, K. (1994). The location of culture. London: Routledge.

Bhattacharya, K. (2009). Negotiating shuttling between transnational experiences: A decolonizing approach to performance ethnography. Qualitative Inquiry, 1, (5). 10611081.

Carspecken, P. F. (1996). Critical ethnography in educational research: A theoretical and practical guide. New York: Routledge.

Chinn, P. W. U. (2007). Decolonizing methodologies and indigenous knowledge: The role of culture, place and personal experience in professional development. Journal of Research in Science Teaching, 44(9), 1247- 1268.

Christine, M. (2008). Review of the book Decolonizing methodologies: Research and indigenous people by L. T. Smith. InterActions: UCLA Journal of Education and Information Studies, 2(4), 1-6.

Creswell, J. (2008). Educational research: Planning, conducting, and evaluating quantitative and qualitative research (3rd ed.). Upper Saddle River, New Jersey: Pearson Education.

Denzin, N. K., \& Lincoln, Y. S. (Eds.). (2005). The SAGE handbook of qualitative research ( $3^{\text {rd }}$ ed.). Thousand Oaks, CA: SAGE Publications.

Fricker, M. (2007). Epistemic injustice. Oxford: Oxford University Press.

Gautam, S. (2011). Literacy Sucks! Voice of Tharu women (Unpublished MPhil dissertation). Kathmandu University, Nepal.

Gergen, K. J. (2009). Relational being: Beyond self and community. New York: Oxford University Press.

Grbich, C. (2004). New approaches in social research. London: Sage Publications. Guneratne, A. (2002). Many tongues, one people: The making of Tharu identity in Nepal. New York: Cornell University Press. 
Hamdan, A. K. (2009). Narrative inquiry as a decolonizing methodology. Interaction: UCLA Journal of Education and Information studies, 5(2), 1-21.

Harvey, G. (2003). Guesthood as ethical decolonizing research method. Numen, 50(2), 125145.

Kincheloe, J. L., \& Mclaren, P. (2005). Rethinking critical theory and qualitative research. In N. K. Denzin \& Y. S. Lincoln (Eds.), The Sage handbook of qualitative research $\left(3^{\text {rd }} \mathrm{ed}\right.$, pp. 303-342). Thousand Oaks, CA: Sage Publications.

Kincheloe, J. L. (2001). Describing the bricolage: Conceptualizing a new rigor in qualitative research. Qualitative Inquiry, 7(6), 679-692.

Lincoln, Y. S, \& Gonazalez, E. M. (2008). The search for emerging decolonial methodologies in qualitative research: Further strategies for libratory and democratic inquiry. Qualitative Inquiry, 14(5), 784- 805.

Luitel, B. C. (2009). Culture, worldview and transformative philosophy of Mathematics education in Nepal: A cultural-philosophical inquiry (Unpublished doctoral dissertation). Curtin University of Technology, Perth, Australia.

Maldonado- Torres, N. (2011). Thinking through the decolonial turn: Post-colonial interventions in theory, philosophy and critique - An introduction. Transmodernity: Journal of Peripheral Cultural production of the Luso-Hispanic World,1(2). 1-15.

Mingnolo, W. D. (2009). Epistemic disobedience, independent thought and de-colonial freedoom. Theory Culture and Society, 1- 23.

Moosa-Mitha, M. (2005). Situating anti-oppressive theories within critical and differencecentered perspectives. In L. Brown \& S. Strega (Eds.), Research as resistance: Critical, indigenous and anti-oppressive approaches (15-29). Toronto: Canadian Scholars' Press.

Quayson, A. (2000). Postcolonialism: Theory, practice or process? Cambridge: Polity Press. Robson, C. (2002). Real world research (2nd ed.). Malkden, MA: Blackwell.

Semali, L. M., \& Kincheloe, J. L. (1999). Introduction: What is indigenous knowledge and why should we study it? In L. M. Semali \& J. L. Kincheloe (Eds.), What is indigenous knowledge? Voices from the academy (pp. 3-58). New York: Falmer Press.

Sivananda (1994). Introduction. In S. Sivanada (Ed.), Mokshya Geeta (5-9). Rishikesh: Sivananda Ashram.

Spivak, G. (1988). Can subaltern speak? In C. Nelson \& L. Grossberg (Eds.), Marxism and the interpretation of culture (pp. 271- 316) ). London: Macmillian. 
Spry, T. (2001). Performing autoethnography: An embodied methodological praxis. Qualitative Inquiry, 7(6), 706-732.

Taylor, P. C. (2008). Multi-paradimatic research design spaces for cultural studies researcher embodying post colonial theorizing. Cultural Studies of Science Education, 3(4), 881889.

Willis, J. (2007). Foundations of qualitative research: Interpretive and critical approaches. Thousand Oaks, CA: Sage.

Wilson, C. (2001). Decolonizing methodologies: Research and indigenous peoples by Linda Tuhiwai Smith, 1999, Zed Books, London. Social Policy Journal of New Zealand, 17, 214- 217.

Wobst, H. M. (2005). Power to the (Indigenous) past and present. In C. S. Wobst (Ed.), Indigenous archaeologies: Decolonizing theory and practice (pp. 15-29). London: Routledge. 